\title{
Editorial
}

\section{Time to act...}

It gives us immense pleasure to continue publishing the HYDRO Nepal journal, the first of its kind in Nepal. The first souvenir edition of the journal has been circulated in 20 countries and warmly acknowledged by its readers. HYDRO Nepal's mission is to provide a network for sharing technical information and expertise on Water, Energy and Environment sector. It aims to bring people with a common interest together. We hope that the authoritative articles written by experts will be an invaluable source of resources for anyone interested in any aspect of water resources development.

The abundant water resources of Nepal hold the key for the overall socio-economic development of our nation. The development of hydro power does not only bring a social transformation at the local level but also creates a resources pool.

The escalating prices of oil, gas and coal in the international market have again emphasized the significance in developing hydro-electric power. Against a techno-economically viable hydroelectric power of 42,000 MW, the actual installed capacity is only 551.10 MW in Nepal. This scenario clearly indicates the vast underutilization of the available hydro-potential within the country, thus, inducing painful load shedding. However, there have been some recent positive initiatives in removing hurdles; such as, removing the EIA requirement for up to $10 \mathrm{MW}$ projects, increasing the license fee to discourage license holdings and initiatives to amend the Electricity Act. But, these are not enough.

There are still numerous constraints, impediments and risks in addition to the political instability that hamper the growth of the hydropower industry in the country. Besides, fulfilling insatiable and vast local demands at project areas further make it a Herculean task to complete hydropower project in Nepal. The concerned governmental agencies have their own priorities and agendas to follow and enforce irrespective of national requirements. Hence, it is imperative to create an all powerful high commission to determine and define the core and priority areas of the nation for its development.

HYDRO Nepal calls for collective and collaborative efforts of all the stakeholders to make an effort for eliminating the constraints and hurdles, and create conducive environment in harnessing the huge hydropotential of the country for the benefit of the nation and its people.

It is time to declare a Hydropower Decade (2008-18), to build a new Nepal.

Jeewan P. Thanju Editor-in-Chief 